\title{
Densidade populacional do nematoides-das-lesões-radiculares em cana-de-açúcar em função de cultivares, manejo do palhiço e escarificação do solo
}

\author{
Gabrielle Regina Miguel Barbosa', Guilherme Lafourcade Asmus²
}

${ }^{1}$ Universidade Estadual de Mato Grosso do Sul, Unidade Universitária de Aquidauana, Aquidauana, Mato Grosso do Sul, Brasil. Email: gbarbosa.florestal@gmail.com

${ }^{2}$ Empresa Brasileira de Pesquisa Agropecuária, Centro de Pesquisa Agropecuária do Oeste, Dourados, Mato Grosso do Sul, Brasil. E-mail: guilherme.asmus@embrapa.br

Recebido: 24/05/2018; Aceito: 11/02/2019.

\section{RESUMO}

A expansão do setor sucroalcooleiro suscitou preocupação quanto a questões que afetam a produtividade, tais como a presença de fitonematoides e as práticas de manejo cultural. O objetivo deste trabalho foi analisar a comunidade de nematoides do gênero Pratylenchus em cultivares de cana-de-açúcar plantados em solo submetido ou não à escarificação e ao aleiramento do palhiço residual da colheita. Foi conduzido experimento de campo em duas áreas, com e sem escarificação, nas quais foram plantadas 15 cultivares de cana-de-açúcar em subparcelas com e sem aleiramento do palhiço sobre as linhas de plantio. Anualmente, foram quantificados os nematoides do gênero Pratylenchus, no solo e nas raízes das plantas. Houve diferenças na densidade populacional do nematoidedas-lesões-radiculares em função do cultivar de cana-de-açúcar. O cultivar RB 92579 mostrou-se suscetível ao nematoide-das-lesões-radiculares. A não escarificação exerce limitação ao número de nematoides-das-lesõesradiculares, e a manutenção da palha sobre a superfície do solo em área total após a colheita de três safras não exerceu influência sobre a densidade populacional do nematoide-das-lesões-radiculares no solo ou nas raízes de diferentes cultivares de cana-de-açúcar. Após quatro anos de cultivo de cana-de-açúcar, a população de $P$. zeae prevaleceu sobre a de $P$. brachyurus.

Palavras-chave: Saccharum officinarum, colheita mecanizada, cultivo mínimo, Pratylenchus.

\section{Population density of the root-lesion nematode in sugarcane as a function of cultivars, straw management and soil scarification}

\begin{abstract}
The expansion of the sugar and alcohol sector in the state of Mato Grosso do Sul, Brazil, has raised concerns about the issues affecting productivity, including the presence of root-lesion nematodes and the soil management employed, as well as the management of straw, as a result of mechanized harvesting of raw cane. The objective of this study was to analyze the community of nematodes of the genus Pratylenchus in sugarcane cultivars planted in soil submitted to scarification and to the enclave of residual sugar cane straw. A field experiment was carried out in two areas, with and without scarification, in which 15 sugarcane cultivars were planted in subplots with and without de-chaining of the straw on the planting lines. Yearly the nematodes of the genus Pratylenchus were quantified in soil and roots of the sugarcane plants. Differences in the population density of the root-lesion nematode as a function of the sugarcane cultivars were reported. The cultivar RB 92579 was susceptible to rootlesion nematode. Non-scarification limits the number of root-lesion nematodes in soil cultivated with sugarcane and the maintenance of the straw on the soil surface, in total area after the harvest of three harvests, has no influence on the population density of root-lesions nematodes in the soil or roots of different sugarcane cultivars. After four years of sugar cane cultivation, the population of $P$. zeae prevailed over that of $P$. brachyurus.
\end{abstract}

Keywords: Saccharum officinarum, mechanized harvest, minimum tillage, Pratylenchus. 


\section{Introdução}

A expansão do setor sucroalcooleiro no Brasil ocasionou relevante aumento na produção de cana-deaçúcar, que na safra de 2015/2016 alcançou a marca de 658 milhões de toneladas em cerca de nove milhões de hectares de área plantada; um incremento de três milhões de hectares em relação a 2005/06 (CONAB, 2015; 2017).

Para manter níveis elevados de produção e produtividade, é importante que os fatores limitantes sejam reduzidos ao máximo. Dentre os elementos que limitam a produtividade dos canaviais no Brasil, destacam-se o uso inadequado das tecnologias de campo, do preparo de solo à pós-colheita, e problemas fitossanitários (Bellé et al., 2014).

Os fitonematoides configuram-se como os principais fatores de ordem fitossanitária que reduzem significativamente a produtividade de cana-de-açúcar no Brasil (Dinardo-Miranda et al., 2011). Dependendo da espécie, do nível populacional, do tipo de solo e do cultivar de cana-de-açúcar, as reduções devidas a fitonematoides podem atingir 50\% (Dinardo-Miranda, 2008). No Brasil, as espécies de nematoides pertencentes aos gêneros Meloidogyne Goeldi (nematoides das galhas) e Pratylenchus Filipjev (nematoides causadores de lesões radiculares) são consideradas as mais importantes economicamente (Goulart, 2008). Os nematoides-das-lesões estão distribuídos em grande parte das regiões produtoras de cana-de-açúcar (Castillo e Vovlas, 2007) e, quando em alta densidade populacional, podem comprometer o desenvolvimento vegetal, em função dos danos causados às raízes parasitadas, levando a reduções expressivas na produtividade (Dinardo-Miranda et al., 2001).

Dentre os métodos indicados de controle das populações dos nematoides-das-lesões destaca-se a escolha do cultivar com menor suscetibilidade a esse parasita (Novaretti et al., 1998). No entanto, estudos relacionados à resistência genética de cultivares de cana-de-açúcar ao gênero Pratylenchus são escassos, considerando, principalmente, os materiais genéticos mais adaptados à região Centro-Sul do Brasil, sendo importante a investigação do efeito dos cultivares mais utilizados na região sobre a população de Pratylenchus spp.

Estudos que relacionam níveis de compactação do solo e comunidades de nematoides são escassos na literatura (Cardoso et al., 2012). No entanto, experimentos conduzidos por Sousa et al. (2014) permitiram associar o aumento do grau de compactação do solo com a redução do número de fitonematoides. $\mathrm{O}$ mesmo ocorreu em estudos de relações entre a nematofauna e a resistência mecânica do solo à penetração de raízes em área de cultivo de cana-deaçúcar (Cardoso et al., 2012).

No manejo pós-colheita, o aleiramento do palhiço da cana-de-açúcar na entrelinha facilita a rebrota das soqueiras, principalmente em regiões mais frias, protege o solo contra a erosão e incorpora matéria orgânica ao solo, o que, em longo prazo, afeta positivamente a produtividade da cultura (Sá et al., 2015; Hassuani et al., 2005).

$\mathrm{Na}$ Austrália, em áreas em que resíduos da colheita permaneceram no campo, houve supressão de nematoides fitoparasitos com relação à área em que foi retirada a palha da cana-de-açúcar das linhas de cultivo (Stirling et al., 2011). Não há relatos de resultados dessa prática em condições brasileiras.

Neste contexto, o objetivo deste trabalho foi analisar a comunidade de nematoides do gênero Pratylenchus em cultivares de cana-de-açúcar, em solo submetido ou não à escarificação e ao aleiramento do palhiço residual da cultura.

\section{Material e Métodos}

O trabalho de campo foi conduzido na Usina São Fernando Açúcar e Álcool, no município de DouradosMS, localizada nas coordenadas geográficas $22^{\circ} 16^{\prime}$ de latitude sul e $54^{\circ} 55^{\prime}$ de longitude oeste, com altitude de $434 \mathrm{~m}$. O clima da região, de acordo com a classificação de Köppen, é do tipo Cwa (Clima mesotérmico úmido, verões quentes e invernos secos), com temperatura dos meses mais frios (junho e julho) inferior a $18^{\circ} \mathrm{C}$ e do mês mais quente (janeiro) superior a $22^{\circ} \mathrm{C}$. Na região, o total de chuvas no verão supera em dez vezes a menor precipitação mensal, que é no mês de julho (Fietz e Fish, 2008). O solo da área onde foi conduzido o experimento foi classificado como Latossolo Vermelho distroférrico (LVdf), e o experimento foi instalado em área anteriormente ocupada com pastagem para pecuária de corte.

Os tratamentos consistiram em dois tipos de preparo do solo: com e sem escarificação; 15 cultivares, sendo eles: SP91-1049, SP83-2847, RB937570, RB867515, RB855536， RB835054， RB92579, RB966928, RB855453, SP80-3280, RB935744, RB855156, IACSP95-5000, RB965902 e SP81-3250; e dois tipos de manejo do palhiço: sem e com remoção do palhiço de cana sobre as linhas e, neste caso, enleiramento do palhiço nas entrelinhas. O preparo do solo foi convencional em toda a área experimental. No entanto, para se avaliar os efeitos da escarificação, a área foi dividida em dois campos: o que recebia a escarificação do solo (campo 1) e o não escarificado (campo 2).

O plantio do primeiro ciclo da cultura foi realizado entre os meses de maio e junho de 2011, aplicando-se 
$500 \mathrm{~kg} \mathrm{ha}^{-1}$ de N-P-K nas doses 05-25-25 nos sulcos em toda área do experimento.

No campo que recebeu escarificação juntamente com a adubação, foi cortada a palha da cana-de-açúcar presente no campo com um disco cortador, e para o processo de escarificação, uma haste rígida acoplada a um trator agrícola passou no meio das entrelinhas de cultivo, seguido de dois discos corrugados para revolvimento das camadas mais superficiais do solo; posteriormente, um rolo de grade realizou uma leve compactação no solo, cuidando para que o teor de umidade fosse adequado para a operação.

Ocorreram, durante o período do estudo, quatro colheitas mecanizadas, em agosto de 2012, novembro de 2013 e 2014 e outubro de 2015. Após cada colheita, houve a escarificação do primeiro campo, seguida do aleiramento do palhiço nos campos 1 e 2 .

$\mathrm{O}$ conjunto de máquinas utilizado para realizar o aleiramento do palhiço foi um ancinho aleirador, com três pares de rodas com $145 \mathrm{~cm}$ de diâmetro e 40 dentes flexíveis por roda, acionado por contato das rodas com a palha sem a necessidade de tomada de potência. A movimentação vertical do equipamento se deu por meio de acionamento hidráulico, e o tracionamento foi efetuado por um trator com $165 \mathrm{cv}$ de potência, sendo que o rodado do trator passava em todas as linhas.

Para avaliar a comunidade de Pratylenchus spp., foram coletadas amostras de solo e raízes de cana-deaçúcar das subparcelas (12 subamostras de solo na profundidade de 0,0 a $0,2 \mathrm{~m}$ subparcela $^{-1}$ e $50 \mathrm{~g}$ de raízes de 5 plantas da linha central de cada subparcela), sempre após as operações de colheita, escarificação e aleiramento terem sido realizadas.

Cada subamostra de solo foi coletada da região da rizosfera da linha central de cada subparcela com auxílio de um trado, na profundidade de 0,0 a $0,2 \mathrm{~m}$. As subamostras foram misturadas e homogenizadas para formarem amostras compostas, que foram armazenadas em sacos plásticos e vedadas para evitar a perda de umidade. Em seguida, transportadas para o Laboratório de Nematologia da Embrapa Agropecuária Oeste, em Dourados, MS, onde permaneceram sob refrigeração, a $4^{\circ} \mathrm{C}$, até a realização das extrações.

Para a extração dos nematoides, utilizou-se $200 \mathrm{~g}$ de solo e $10 \mathrm{~g}$ de raízes de cada amostra composta. Para a extração dos nematoides do solo, utilizou-se o método flutuação-sedimentação-peneiramento (Flegg e Hopper, 1970), com posterior clarificação pela técnica de flotação centrífuga em solução de sacarose (Jenkins, 1964).

Para a extração dos nematoides das raízes, utilizouse a técnica de trituração em solução $0,5 \%$ de hipoclorito de sódio e posterior clarificação por centrifugação em solução de sacarose (Coolen e D’Herde, 1972). Após extraídos, os nematoides foram inativados em banho-maria a $55^{\circ} \mathrm{C}$ por 5 minutos e armazenados em formalina (2\%) até que fossem feitas as quantificações.

A contagem foi realizada em alíquotas de 1,0 mL, em lâmina de contagem de Peters, sob microscópio óptico. O número total de fitonematoides em cada amostra composta foi obtido pela multiplicação do número de espécimes presentes nas alíquotas pelo volume total da amostra.

A cada ano, para a identificação da espécie de Pratylenchus presente nas amostras, 20 fêmeas foram submetidas à avaliação quanto às características morfométricas (Gonzaga et al., 2016).

O delineamento experimental foi o de blocos casualizados com parcelas subdivididas, com quatro repetições. As parcelas foram constituídas de seis linhas de cana-de-açúcar com 15 metros de comprimento contendo os cultivares, e as subparcelas foram constituídas de três linhas com e sem aleiramento do palhiço. Todas as amostragens foram feitas nas duas linhas centrais de cada subparcela, estabelecendo-se as linhas mais externas como bordaduras laterais e deixando um metro de bordadura nas extremidades da parcela. Os dados da estimativa do número de nematoides foram transformados em $(x+0,5)^{0,5}$.

Os resultados obtidos foram submetidos à análise de variância e as médias das populações, presentes no solo e raízes das diferentes cultivares, foram agrupadas pelo teste de Scott- Knott ( $\mathrm{p}>0,05)$.

\section{Resultados e Discussão}

As análises morfométricas evidenciaram a presença de duas espécies de Pratylenchus na área experimental; $P$. brachyurus e $P$. zeae, que, segundo Dinardo-Miranda et al. (2000), são as espécies do gênero mais comuns em canaviais. A análise de variância mostrou não houve interação significativa entre os diferentes fatores cultivares, escarificação do solo e aleiramento do palhiço quanto ao número de nematoides-das-lesõesradiculares, no solo ou nas raízes.

De maneira geral, a densidade populacional do nematoide-das-lesões-radiculares foi baixa, variando de 1,66 (2014) a 415,61 indivíduos (2013) por $10 \mathrm{~g}$ de raízes, e de 3,12 (2012) a 109, 37 (2015) por 200 cc de solo, dependendo do cultivar (Tabela 1). Estudos de densidade populacional de Pratylenchus classificam como baixa infestação números inferiores a centenas de indivíduos por $10 \mathrm{~g}$ de raízes e $200 \mathrm{cc}$ de solo em cultivo de cana-de-açúcar (Dinardo-Miranda et al., 2003; Novaretti et al., 1998; Oliveira et al., 2008).

Na primeira avaliação (2012), não houve diferenças significativas que determinassem a influência dos cultivares sobre a comunidade infestante, tanto nas amostras de raízes quanto de solo. 
Nas raízes, essa homogeneidade estatística encontrada pode ser devido ao pouco tempo entre o plantio e a amostragem. Conforme Tokeshi (1997), dificilmente haverá problema com nematoides em solos com pouco tempo de plantio, pois o equilíbrio biológico mantém os nematoides sob controle e abaixo do nível de danos às plantas, não permitindo, assim, a percepção do efeito dos cultivares no primeiro ano. Esse equilíbrio biológico inicial, que mantém os nematoides em pequenas quantidades, pode ser observado nas amostras de solo no primeiro ano de levantamento, em que o grau de infestação foi baixo, com médias variando de 3,1 a 11,2 indivíduos a cada $200 \mathrm{cc}$ de solo amostrado.

Em 2013, foram observadas diferentes quantidades de Pratylenchus nas raízes e no solo, em função dos cultivares. Considerando-se o número de nematoides em 10 g de raízes, os cultivares de cana-de-açúcar se agruparam em quatro categorias, sendo SP91-1049, RB855453, RB966928, RB855536, RB855156, RB965902 e SP81-3250 os que apresentaram maior resistência à multiplicação do nematoide, com baixo nível de infestação (Tabela 1). Por outro lado, os cultivares RB835054 e RB 92579 apresentaram, respectivamente, as maiores populações do nematoide em seu sistema radicular, indicando serem favoráveis à reprodução dos nematoides-das-lesões-radiculares. Para as amostras de solo, apenas o cultivar RB 925797 se diferenciou dos demais, apresentando maior quantidade de indivíduos do gênero Pratylenchus na microbiota do solo.

Tabela 1. Número de nematoides-das-lesões-radiculares ( $P$. brachyurus e $P$. zeae) em amostras de solo e de raízes, em parcelas cultivadas com diferentes cultivares de cana-de-açúcar ao longo de quatro anos, na Usina São Fernando, Dourados, MS.

\begin{tabular}{|c|c|c|c|c|}
\hline \multicolumn{5}{|c|}{ Ano } \\
\hline \multirow[t]{2}{*}{ Cultivar } & 2012 & 2013 & 2014 & 2015 \\
\hline & \multicolumn{4}{|c|}{ Raízes (número de indivíduos / 10 g) } \\
\hline SP91-1049 & $46,91 \mathrm{a}$ & $31,36 \mathrm{a}$ & $25,00 \mathrm{e}$ & $85,85 \mathrm{a}$ \\
\hline SP83-2847 & 73,99 a & $158,44 \mathrm{~b}$ & $12,50 \mathrm{~d}$ & $26,31 \mathrm{a}$ \\
\hline RB937570 & $67,91 \mathrm{a}$ & $193,78 \mathrm{~b}$ & $8,33 \mathrm{c}$ & $190,41 \mathrm{a}$ \\
\hline RB867517 & $107,51 \mathrm{a}$ & $274,35 \mathrm{c}$ & $6,25 \mathrm{~b}$ & 85,16 a \\
\hline RB855536 & $119,02 \mathrm{a}$ & $57,06 \mathrm{a}$ & $5,00 \mathrm{~b}$ & $64,48 \mathrm{a}$ \\
\hline RB835054 & 92,76 a & $406,28 \mathrm{~d}$ & $4,16 \mathrm{~b}$ & $123,72 \mathrm{a}$ \\
\hline RB92579 & $66,93 \mathrm{a}$ & $415,61 \mathrm{~d}$ & $3,57 \mathrm{~b}$ & $192,22 \mathrm{a}$ \\
\hline RB966928 & 58,38 a & $46,55 \mathrm{a}$ & $3,80 \mathrm{~b}$ & 335,98 a \\
\hline RB855453 & $73,21 \mathrm{a}$ & $35,67 \mathrm{a}$ & $2,77 \mathrm{a}$ & $69,94 \mathrm{a}$ \\
\hline SP80-3280 & $62,64 \mathrm{a}$ & $260,59 \mathrm{c}$ & $2,50 \mathrm{a}$ & $169,36 \mathrm{a}$ \\
\hline RB935744 & $130,53 \mathrm{a}$ & $188,78 \mathrm{~b}$ & $2,27 \mathrm{a}$ & $138,15 \mathrm{a}$ \\
\hline RB855156 & $75,33 \mathrm{a}$ & $73,53 \mathrm{a}$ & $2,08 \mathrm{a}$ & $42,81 \mathrm{a}$ \\
\hline IACSP95-5000 & 80,71 a & $199,42 \mathrm{~b}$ & $1,92 \mathrm{a}$ & $74,25 \mathrm{a}$ \\
\hline RB965902 & 95,88 a & 59,39 a & $3,81 \mathrm{~b}$ & 74,68 a \\
\hline SP81-3250 & $80,10 \mathrm{a}$ & $76,92 \mathrm{a}$ & $1,66 \mathrm{a}$ & 51,07 a \\
\hline $\mathrm{p}$ & 0,6643 & 0,0000 & 0,0000 & 0,1224 \\
\hline \multirow[t]{2}{*}{$\mathrm{CV}(\%)$} & 65,26 & 51,71 & 19,97 & 119,38 \\
\hline & \multicolumn{4}{|c|}{ Solo (número de indivíduos/ 200 cc) } \\
\hline SP91-1049 & $7,50 \mathrm{a}$ & $11,25 \mathrm{a}$ & $8,13 \mathrm{a}$ & $20,00 \mathrm{a}$ \\
\hline SP83-2847 & $7,50 \mathrm{a}$ & $33,75 \mathrm{a}$ & $32,50 \mathrm{a}$ & $33,75 \mathrm{a}$ \\
\hline RB937570 & $3,12 \mathrm{a}$ & $25,00 \mathrm{a}$ & $25,00 \mathrm{a}$ & $41,88 \mathrm{a}$ \\
\hline RB867517 & $3,75 \mathrm{a}$ & $21,87 \mathrm{a}$ & $11,25 \mathrm{a}$ & $50,62 \mathrm{a}$ \\
\hline RB855536 & $11,25 \mathrm{a}$ & $12,50 \mathrm{a}$ & $8,13 \mathrm{a}$ & $20,00 \mathrm{a}$ \\
\hline RB835054 & $10,00 \mathrm{a}$ & $46,25 \mathrm{a}$ & $36,25 \mathrm{a}$ & $109,37 \mathrm{a}$ \\
\hline RB92579 & $6,87 \mathrm{a}$ & $90,00 \mathrm{~b}$ & $18,75 \mathrm{a}$ & $66,87 \mathrm{a}$ \\
\hline RB966928 & $6,87 \mathrm{a}$ & $5,00 \mathrm{a}$ & $9,38 \mathrm{a}$ & $23,13 \mathrm{a}$ \\
\hline RB855453 & $3,75 \mathrm{a}$ & $9,37 \mathrm{a}$ & $8,75 \mathrm{a}$ & $30,00 \mathrm{a}$ \\
\hline SP80-3280 & $8,12 \mathrm{a}$ & $27,50 \mathrm{a}$ & $22,50 \mathrm{a}$ & $43,75 \mathrm{a}$ \\
\hline RB935744 & $7,50 \mathrm{a}$ & $23,12 \mathrm{a}$ & $39,38 \mathrm{a}$ & $46,25 \mathrm{a}$ \\
\hline RB855156 & $4,37 \mathrm{a}$ & $11,25 \mathrm{a}$ & $18,13 \mathrm{a}$ & 20,62 a \\
\hline IACSP95-5000 & $10,00 \mathrm{a}$ & $7,50 \mathrm{a}$ & $34,38 \mathrm{a}$ & 29,37 a \\
\hline RB965902 & $10,00 \mathrm{a}$ & $13,13 \mathrm{a}$ & $8,75 \mathrm{a}$ & $21,87 \mathrm{a}$ \\
\hline SP81-3250 & $4,37 \mathrm{a}$ & $6,87 \mathrm{a}$ & $13,75 \mathrm{a}$ & $20,62 \mathrm{a}$ \\
\hline $\mathrm{p}$ & 0,6537 & 0,0000 & 0,1224 & 0,0748 \\
\hline $\mathrm{CV}(\%)$ & 125,68 & 97,11 & 119,38 & 85,81 \\
\hline
\end{tabular}

Médias seguidas da mesma letra nas colunas possuem verossimilhança entre si pelo teste de Scott Knott (p>0,05). * Dados originais. Para fins de análise, os dados foram transformados em $(\mathrm{x}+0,5)^{0,5}$. 
Resultados semelhantes foram percebidos por Noronha et al. (2017), que estudando a ocorrência de fitonematoides em 10 cultivares de cana, verificaram a maior população de Pratylenchus no cultivar RB 92579. Os dados encontrados por Noronha et al. (2017) podem sugerir que a taxa de reprodução do nematoide seja favorecida por esse cultivar, contribuindo para o aumento de sua densidade populacional no solo.

O cultivar SP 91-1049, em 2014, foi o que apresentou a maior quantidade de Pratylenchus nas raízes em relação aos demais, no entanto, quando comparado aos anos anteriores, foi possível observar uma acentuada queda no quantitativo de nematoides em suas raízes. Quando comparado aos anos de 2012 e 2013, nota-se uma redução no número de indivíduos presente nas raízes dos cultivares analisados em 2014.

Uma possível explicação para esse fato foi a taxa de precipitação do ano de 2014, considerada a menor dos últimos 30 anos na região de Dourados (Embrapa, 2015), desfavorecendo, desse modo, a sobrevivência dos nematoides, já que solos secos restringem a movimentação dos nematoides até as raízes e aumentam a sua taxa de mortalidade (Tihohod, 1993).

No ano de 2015 não foram observadas diferenças nas quantidades de Pratylenchus spp. nos sistemas radiculares dos cultivares de cana-de-açúcar, tampouco no solo cultivado com esses cultivares. Embora a população do nematoide tenha aumentado em relação ao ano de 2014, possivelmente pela regularização dos regimes pluviométricos, o desenvolvimento radicular foi mais favorável, propiciando também o ataque e o aumento da densidade populacional dos nematoidesdas-lesões (Vasconcelos e Dinardo-Miranda, 2011).

A escarificação do solo não teve efeito sobre a população de Pratylenchus spp. nas raízes de cana-deaçúcar em relação à não escarificação, em nenhum dos anos em que foi avaliado. Por outro lado, em 2012 e 2014, solos que não passaram por escarificação apresentaram número significativamente menor de Pratylenchus do que solos escarificados (Tabela 2). No que diz respeito a nematoides em cana-de-açúcar, Sousa et al. (2014) observaram que o aumento de níveis de compactação do solo proporcionou redução na multiplicação de Meloidogyne incognita.

Considerando-se o fato de que Pratylenchus spp. é um nematoide endoparasita migrador e que sua multiplicação depende da quantidade de raízes de plantas suscetíveis disponíveis ao parasitismo, é provável que a escarificação, ao diminuir a compactação, tenha permitido maior crescimento radicular da cana-de-açúcar, proporcionando maior volume de raízes para o crescimento populacional do nematoide.

A remoção do palhiço sobre as linhas de cultivo (aleiramento) ou a sua manutenção em área total (enleiramento) não tiveram efeitos na população de Pratylenchus, tanto em raízes quanto no solo cultivado com 16 diferentes cultivares (Tabela 3).

De acordo com Ripoli e Ripoli (2008), a alteração no sistema de colheita da cana-de-açúcar, que substitui a colheita manual da cana queimada pela colheita mecanizada sem queima prévia, ou colheita da cana crua, resulta em uma maior deposição de palha no campo, com valores chegando a $15 \mathrm{t} \mathrm{ha}^{-1}$ de massa seca. Essa grande quantidade de palhiço no campo, aliada à ausência do fogo, ocasiona alterações nos ecossistemas, afetando o microclima do solo, com o aumento de umidade e redução da radiação solar sobre o solo e a manutenção de formas biológicas que antes eram destruídas pelo fogo, causando mudanças no setor de produção (Dinardo-Miranda e Fracasso, 2013).

Ao mesmo tempo em que a manutenção da palha em linha de cultivo (enleiramento) reduz a incidência solar sobre o solo, podendo propiciar um microclima favorável ao desenvolvimento de fitonematoides (Silva et al., 2006), Dinardo-Miranda e Fracasso (2013) sugerem que possa ocorrer o inverso, a supressão dessas populações devido ao aumento de matéria orgânica depositada no solo, permitindo a infestação de outros microorganismos que afetam a população de nematoides e a liberação de substâncias de efeito nematicidas durante a decomposição da matéria orgânica.

Tabela 2. Número de nematoides-das-lesões-radiculares ( $P$. brachyurus e $P$. zeae) em amostras de raízes de cana-de-açúcar e de solo, em função do preparo do solo com e sem escarificação, ao longo de quatro anos na Usina São Fernando, Dourados-MS.

\begin{tabular}{|c|c|c|c|c|}
\hline & & & & \\
\hline & 2012 & 2013 & 2014 & 2015 \\
\hline & \multicolumn{4}{|c|}{ Raízes (número de indivíduos/10 g) } \\
\hline Escarificado & $79,35 \mathrm{a}$ & $174,96 \mathrm{a}$ & $5,80 \mathrm{a}$ & $112,60 \mathrm{a}$ \\
\hline Não Escarificado & $84,90 \mathrm{a}$ & $155,40 \mathrm{a}$ & $5,62 \mathrm{a}$ & $117,26 \mathrm{a}$ \\
\hline $\mathrm{p}$ & 0,5850 & 0,2206 & 0,7521 & 0,4150 \\
\hline \multirow[t]{2}{*}{ CV $(\%)$} & 65,26 & 51,71 & 19,97 & 119,38 \\
\hline & \multicolumn{4}{|c|}{ Solo (número de indivíduos/200 cc) } \\
\hline Escarificado & $9,08 \mathrm{a}$ & $19,50 \mathrm{a}$ & $24,67 \mathrm{a}$ & $45,33 \mathrm{a}$ \\
\hline Não Escarificado & $4,92 \mathrm{~b}$ & $26,42 \mathrm{a}$ & $14,66 \mathrm{~b}$ & $31,75 \mathrm{a}$ \\
\hline $\mathrm{p}$ & 0,0143 & 0,4538 & 0,0415 & 0,1966 \\
\hline CV $(\%)$ & 125,68 & 97,11 & 119,38 & 85,81 \\
\hline
\end{tabular}

Médias seguidas da mesma letra, nas colunas, não diferem entre si pelo teste $\mathrm{F}$ (5\%). 
Tabela 3. Efeito do desaleiramento do palhiço de cana-de-açúcar sobre a comunidade de nematoides-das-lesões-radiculares $(P$. brachyurus e $P$. zeae) em amostras de solo e de raiz, em experimento conduzido ao longo de quatro anos na Usina São Fernando, Dourados-MS.

\begin{tabular}{|c|c|c|c|c|}
\hline Ano & & & & \\
\hline & 2012 & 2013 & 2014 & 2015 \\
\hline \multicolumn{5}{|c|}{ Raízes (número de indivíduos/10 g) } \\
\hline Aleirado & $79,19 \mathrm{a}$ & $163,91 \mathrm{a}$ & $5,80 \mathrm{a}$ & $92,93 \mathrm{a}$ \\
\hline Enleirado & $85,05 \mathrm{a}$ & $166,45 \mathrm{a}$ & $5,62 \mathrm{a}$ & $136,94 \mathrm{a}$ \\
\hline $\mathrm{p}$ & 0,7564 & 0,0949 & 0,7421 & 0,9056 \\
\hline $\mathrm{CV}(\%)$ & 65,26 & 51,71 & 19,97 & 119,38 \\
\hline \multicolumn{5}{|c|}{ Solo (número de indivíduos/200 cc) } \\
\hline Aleirado & $7,66 \mathrm{a}$ & $21,58 \mathrm{a}$ & $19,08 \mathrm{a}$ & $33,17 \mathrm{a}$ \\
\hline Enleirado & $6,33 \mathrm{a}$ & $24,33 \mathrm{a}$ & $20,25 \mathrm{a}$ & $43,92 \mathrm{a}$ \\
\hline $\mathrm{p}$ & 0,3464 & 0,6686 & 0,7516 & 0,2400 \\
\hline $\mathrm{CV}(\%)$ & 125,68 & 97,11 & 119,38 & 85,81 \\
\hline
\end{tabular}

Médias seguidas da mesma letra nas colunas não diferem entre si pelo teste $\mathrm{F}$ (5\%).

Estudando a eficiência de produtos químicos e naturais para controlar a população de Pratylenchus da cultura da cana-de-açúcar, Oliveira et al. (2005) não observaram efeito da adição de resíduo orgânico na população deste gênero. Desta forma, a homogeneidade estatística encontrada neste trabalho para o efeito dos diferentes manejos do palhiço da cana-de-açúcar sobre a população dos nematoides-das-lesões-radiculares é corroborada por estudos de Oliveira et al. (2008) e Dinardo-Miranda et al. (2003), explicando que, possivelmente, a presença de palha no campo não afete a população de nematoides a curto prazo, sendo necessário conduzir pesquisas com maior duração para investigar se o efeito se manifesta a médio ou longo prazo. De acordo com Dinardo-Miranda e Fracasso (2013), problemas com altas taxas de infestações de nematoides continuam sendo reportados, mesmo em sistema de colheita de cana-crua.

No presente trabalho, houve uma variação, ao longo dos anos, na proporção das duas espécies de Pratylenchus. Na amostragem de 2012, a espécie mais comum foi $P$. brachyurus. No entanto, no decorrer do tempo, a composição relativa da população foi se alterando, de forma que, em 2015, P. zeae passou a ser a espécie prevalente (Figura 1).

A redução do número de indivíduos de $P$. brachyurus em detrimento do aumento da população de $P$. zeae seguiu tendência no cultivo de cana-de-açúcar, relatada por Dinardo-Miranda (2008), evidenciando que a agressividade e a taxa de reprodução de $P$. zeae na cultura da cana são maiores do que as observadas com P. brachyurus.

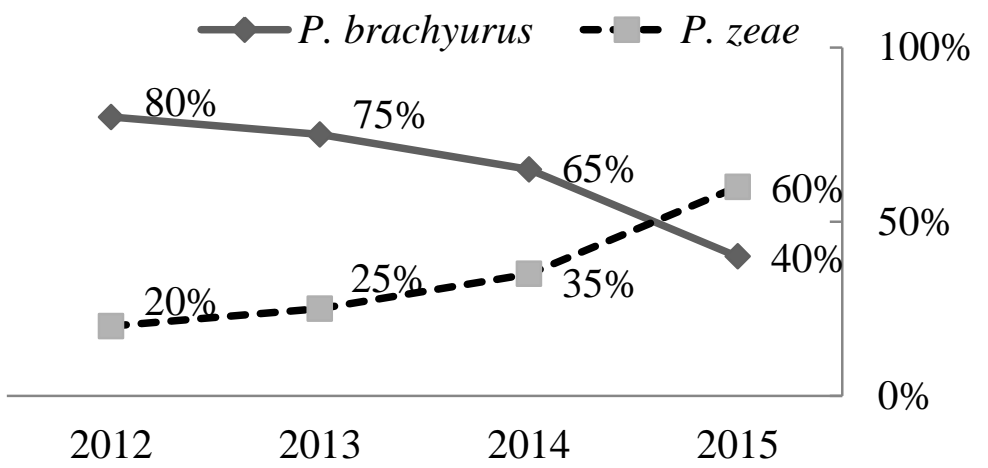

Figura 1. Frequência de ocorrência de espécies do gênero Pratylenchus em área cultivada com cana-de-açúcar ao longo de quatro anos, na Usina São Fernando, Dourados, MS.

\section{Conclusões}

Os resultados obtidos no presente trabalho permitem concluir que:

1) Há diferenças na densidade populacional do nematoide-das-lesões-radiculares em função do cultivar de cana-de-açúcar;

2) O cultivar RB 92579 é suscetível aos nematoidesdas-lesões-radiculares;
3) A não escarificação exerce limitação ao número de nematoides-das-lesões-radiculares em solo cultivado com cana-de-açúcar;

4) A manutenção da palha sobre a superfície do solo em área total após a colheita de três safras não exerceu influência sobre a densidade populacional do nematoide-das-lesões-radiculares no solo ou raízes de diferentes cultivares de cana-de-açúcar; 
5) Após quatro anos de cultivo de cana-de-açúcar, a população de $P$. zeae prevalece sobre a de $P$. brachyurus.

\section{Agradecimentos}

À CAPES (Coordenação de Aperfeiçoamento de Pessoal de Nível Superior), pelo apoio financeiro e concessão da bolsa de estudo, e à Usina São Fernando Açúcar e Álcool, pelo apoio durante a condução dos trabalhos de campo.

\section{Referências Bibliográficas}

Bellé, C., Kulczynski, S.M., Gomes, C.B., Kuhn, P.R., 2014. Fitonematoides associados à cultura da cana-de-açúcar no Rio Grande do Sul, Brasil. Nematropica, 44(1), 207-217.

Cardoso, M.O., Pedrosa, E.M.R., Rolim, M.M., Silva, E.F.F., Barros, P.A., 2012. Effects of soil mechanical resistance on nematode community structure under conventional sugarcane and remaining of Atlantic Forest. Environmental Monitoring and Assessment, 184, 3529-3544.

Castillo, P., Vovlas, N., 2007. Pratylenchus (Nematoda: Pratylenchidae): dignosis, biology, pathogenicity and management. Nematology monographs and perspectives. Brill Leiden, Boston.

Companhia Nacional de Abastecimento (CONAB), 2015. Acompanhamento da safra brasileira. Cana-de-Açúcar: Safra 2015-16: $3^{\circ}$ Levantamento. Brasília, DF.

Companhia Nacional de Abastecimento (CONAB), 2017. Acompanhamento da safra brasileira. Cana-de-Açúcar: Safra 2016-17: $4^{\circ}$ Levantamento. Brasília, DF.

Coolen, W.A., D`Herde, C.J., 1972. A method for the quantitative extration of nematodes from plant tissue. State Agriculture Research Center. Ghent, Belgium.

Dinardo-Miranda, L.L., 2008. Pragas, in: Dinardo-Miranda, L.L., Vasconcelos, A.C.M., Landell, M.G.A., (Ed.), Cana-deaçúcar. Instituto Agronômico, Campinas, p. 349-404.

Dinardo-Miranda, L.L., Fracasso, J.V., 2013. Sugarcane straw and the populations of pests and nematodes. Scientia Agricola, 70(5), 305-310.

Dinardo-Miranda, L.L., Fracasso, J.V., Costa, V.P., 2011. Influência da época de aplicação de nematicida em soqueiras colhidas no inicio da safra sobre as populações de nematoides e a produtividade da cana-de-açúcar. Nematologia Brasileira, 34(2), 106-117.

Dinardo-Miranda, L.L., Gil, M.A.; Menegatti, C.C., 2003. Danos causados por nematoides a cultivares de cana-de-açúcar em cana planta. Nematologia Brasileira, 27(1), 69-73.

Dinardo-Miranda, L.L., Menegatti, C.C., Pivetta, J.P., 2001. Eficiência de nematicidas aplicados no plantio de cana-deaçúcar. Nematologia Brasileira, 25(2), 171-174.
Empresa Brasileira de Pesquisa Agropecuária (EMBRAPA), 2015. Guia Clima: Boletim Agrometereológico. http://www.cpao.embrapa.br/clima/mob/?lc=site/boletins/lista Boletins (Acessado 20 de fevereiro de 2016).

Fietz, C.R., Fish, G.F., 2008. O clima na região de Dourados, MS, segunda ed. Embrapa Agropecuária Oeste, Dourados-MS. (Documentos 92).

Flegg, J.J., Hooper, D.J., 1970. Extraction of free-living stages from soil, in: Southey, J.F., (Ed.), Laboratory methods for working with plant and soil nematodes. Ministry of Agriculture, Fisheries and Food, London, p. 148.

Gonzaga, V., Santos, J.M., Mendonça, R.S., Santos, M.A., 2016. Gênero Pratylenchus. In: Oliveira, C.M.G., Santos, M. A., Castro, L.H.S. (Org.), Diagnose de Fitonematoides. Millennium, Campinas, p. 71-98.

Goulart, A.M.C., 2008. Aspectos gerais sobre nematóides-daslesões-radiculares (gênero Pratylenchus). Planaltina-DF, Embrapa Cerrados, 30 p. (Documentos 219).

Hassuani, S.J.; Leal, M.R.L.V.; Macedo, I.C., 2005. Biomass power generation: sugar cane bagasse and trash. PiracicabaSP, PNUD Brasil, Centro de Tecnologia Canavieira. 216 p.

Jenkins, W.R., 1964. A rapid centrifugal-flotation technique for separating nematodes from soil. Plant Disease Reporter, Califórnia, 48(9), 692-698.

Noronha, M.A., Muniz, M.F.S., Cruz, M.M., Assunção, M.C., Castro, J.M.C., Oliveira, E.R.L., Miranda, C.G.S., Machado, A.C.Z., 2017. Meloidogyne and Pratylenchus species in sugarcane fields in the state of Alagoas, Brazil. Ciência Rural, 47(2), 01-03.

Novaretti, W.R.T., Reis, A.M., Ferraz, L.C.C.B., 1998. Controle químico de Meloidogyne incognita e Pratylenchus zeae em cana-de-açucar com carbofuran e terbufos. Nematologia Brasileira, 22(1), 60-74.

Oliveira, F.S. da, Rocha, M.R. da, Reis, A.J.S., Machado, V.O.F., Soares, R.A.B., 2005. Efeito de produtos químicos e naturais sobre a população de nematoide Pratylenchus brachyurus na cultura da cana-de-açúcar. Pesquisa Agropecuária Tropical, 35(3), 171-178.

Oliveira, F.S. da, Rocha, M.R. da, Teixeira, R.A., Faleiro, V.O., Soares, R.A.B., 2008. Efeito de sistemas de cultivo no manejo de populações de Pratylenchus spp. na cultura da cana-de-açúcar. Nematologia Brasileira, 32(2), 117-125.

Ripoli, T.C.C., Ripoli, M.L.C., 2008. Vantagens do uso do palhiço para queima e produção de vapor. Visão Agrícola, 5(8), 66-68.

Sá, M.A.C. de, Franz, C.A.B., Santos Jr, J.D., Rein, T.A., Bufon, V.B., Carvalho, A.M. de, Muller, A.G., 2015. Manejo do palhiço residual na cultura da cana-de-açúcar no cerrado: primeira aproximação. Embrapa Cerrado, Planaltina (Circular Técnica 27).

Silva, P.R.F., Argenta, G., Sangoi, L., Strieder, M.L., Silva, A.A., 2006. Estratégias de manejo de coberturas de solo no inverno para cultivo do milho em sucessão no sistema semeadura direta. Ciência Rural, 36(3), 1011-1020. 
Sousa, C.C.M., Pedrosa, E.M.R., Rolim, M.M., Pereira Filho, J.V., Souza, A.L.M., 2014. Influência da densidade do solo infestada por nematoide no desenvolvimento inicial de canade-açúcar. Revista Brasileira de Engenharia Agrícola e Ambiental, 18(5), 475-479.

Stirling, G.R., Rames, E., Stirling, A.M., Hamill, S., 2011. Factors associated with the supressiveness of sugarcane soils to plant-parasitic nematodes. Journal of Nematology, 43(3-4), 135-148.

Tihohod, D., 1993. Nematologia agrícola aplicada, segunda ed. FUNEP, Jaboticabal.
Tokeshi, H., 1997. Doenças da cana-de-açúcar. Instituto do Açúcar e do Álcool/ Programa Nacional de Melhoramento da cana-de-açúcar. Planalsucar, Piracicaba.

Vasconcelos, A.C.M. de, Dinardo-Miranda, L.L., 2011. Dinâmica do desenvolvimento radicular da cana-de-açúcar e implicações no controle de nematoides, segunda ed. Adonis, Americana. 